Journal of Advanced Research in Fluid Mechanics and Thermal Sciences

\title{
Numerical Simulation of a Propeller-Type Turbine for In-Pipe Installation
}

\author{
Oscar Dario Monsalve-Cifuentes ${ }^{1,}{ }^{*}$, Jonathan Graciano-Uribe ${ }^{1}$, Diego Andrés Hincapié Zuluaga ${ }^{1}$ \\ 1 Faculty of Engineering, Department of Mechatronics and Electromechanics, Instituto Tecnológico Metropolitano, Robledo Campus, Calle 73 No. \\ 76A-354, Vía al Volador, Medellín, Colombia
}

\section{ARTICLE INFO}

Article history:

Received 3 December 2020

Received in revised form 19 April 2021

Accepted 22 April 2021

Available online 19 May 2021

\section{Keywords:}

In-pipe turbines; Propeller; Savonius; Pico-hydropower; Numerical simulation; Computational Fluid Dynamics; CFD

\section{ABSTRACT}

In this work, a $76 \mathrm{~mm}$ diameter propeller-type turbine is numerically investigated using a parametric study and computational fluid dynamics. The three-dimensional model of the turbine is modeled using data available in the bibliography. A mesh independence study is carried out utilizing a tetrahedron-based mesh with inflation layers around the turbine blade and the pipe wall. The best efficiency point is determined by the maximum hydraulic efficiency of $64.46 \%$, at a flow rate of $9.72 \times 10^{-3} \mathrm{~m}^{3} / \mathrm{s}$, a head drop of $1.76 \mathrm{~m}$, and a mechanical power of $107.83 \mathrm{~W}$. Additionally, the dimensionless distance $y^{+}$, pressure and velocity contours are shown.

\section{Introduction}

Electrical generation and water-saving have become throughout the years a paramount object of investigation as well as a big concern for humanity. As a consequence, the global investment in the micro-pico-electrical generation has increased because there are free-emission, sustainable, and environmentally friendly energy hydro sources [1]. Although the drinking water industry in industrialized regions is one of the most energy-intensive hydraulic-wise sectors, the majority of its energy is consumed inefficiently, which is evident in the surplus of pressure generated within the pipelines by gravity disposition designs and storage systems [2]. Then, pressure-reducing valves (PRVs) are installed in waterworks to control the pressure variation, leading to a wasteful dissipation of energy [3].

Two problems are identified when it comes to water distribution systems. On the one hand, the non-usage of the energy stored within the pipes caused by overpressures and high fluid velocities, which generally is not used for other purposes different than being dissipated [4]. On the other hand, especially for pipes located at remote sites, Dequesene et al., [5] from the French Office for Biodiversity (OFB), states that the water losses in pipe distribution systems reach $20 \%$ at a national level representing roughly 1 billion cubic meters of water per year wasted due to leakages. In this

\footnotetext{
${ }^{*}$ Corresponding author.

E-mail address: oscarmonsalvec5@gmail.com
}

https://doi.org/10.37934/arfmts.83.1.116 
manner, high pressure and pressure fluctuations generate, among other causes, the leakages within the pipes [6].

Therefore, different technologies were investigated, which not only harness the kinetic and potential energy of the fluid to generate hydropower but also helping to solve the prior mentioned problems. Thus, various types of hydrokinetic turbines have been used for in-pipe installation to reduce the usage and to increase the life span of PRVs, allowing for the management and regulation of the pressure spikes in the system, along with an adequate energy conversion for hydropower $[7,8]$. Moreover, the generated hydropower could be injected into the local electrical network or to maintain the power consumption of remote control monitoring systems [9].

Northwest Pipe and Lucid Energy companies developed the patent, which describes a spherical turbine system for micro-hydroelectric generation within a cylindrical pipe for drinkable water distribution to harness the excess of energy [10]. According to the reports by Lucid Energy [11,12], the patent was implemented commercially since 2013 for pipes between 610 and $1575 \mathrm{~mm}$ in diameter, $20 \mathrm{~kW}$ of electric power per turbine, and 120 psi as maximum working pressure, producing electrical energy between 50 and $60 \mathrm{MWh}$ a year.

Likewise, a numerical investigation of a $1.4 \mathrm{~m}$ diameter helical-shaped spherical turbine was conducted by Lee et al., [13] where the use of a circular and rectangular duct was investigated, showing that a rectangular duct improved the power coefficient of the turbine by $4.7 \%$ compared to using a circular one. In like manner, an experimental study in a towing tank of a Gorlov and spherical Darrieus turbines, with 1 and 1.14 m of diameter, respectively, was carried out by Bachant and Wosnik [14], where it was concluded that the Gorlov turbine reached a higher power coefficient of $28 \%$ than that of the spherical turbine of $21 \%$. The results were expected due to the better performance of spherical turbines in the presence of more blockage fluid flows, e.g., pipes.

Less than $1 \mathrm{~m}$ diameter spherical turbines for in-pipe installation were investigated by Oladosu and Koya [15], where a $233.6 \mathrm{~mm}$ diameter turbine was numerically studied reaching mechanical powers of 1080 and $2663 \mathrm{~W}$ for stainless steel and aluminum blades, respectively. The generation of maximum head loss was 9.7\%. Similarly, Yeo et al., [16] analyzed computationally a novel spherical turbine of $894.08 \mathrm{~mm}$ in diameter, in which the maximum numerical efficiency reached a value of $22 \%$ at a tip speed ratio of 2.4 and a clearance of $12 \%$.

Additionally, Yang et al., [17] carried out an experimental and numerical study of Darrieus spherical and Savonius turbines with diameters of 183.6 and $180 \mathrm{~mm}$, respectively. It was shown that for a given working condition, the critical flow rate for the self-start of the turbine, the tip speed ratio, and the power coefficient resulted in higher values for the spherical turbine compared to the Savonius. Lastly, Langroudi et al., [18] made a parametric, theoretical, numerical, and experimental study of a spherical turbine of $92 \mathrm{~mm}$ in diameter with helical (twisted) blades. Parameters as the turbine height, number, initial angle of attack, and twist angle of the turbine blades, were taken into account for the parametric study. The results showed that as the number and the initial angle of attack of the turbine blades were increased, the higher the coefficients of power and pressure were, but at the expense of the increment of the possibility of cavitation.

In contrast, cross-flow turbines as the Michel-Banki type also have undergone investigations for in-pipe installation. In particular, the studies of Jiyun et al., [19] showed an experimental and numerical analysis of the development of a vertical-axis cross-flow turbine of $98 \mathrm{~mm}$ in diameter, inline blocks to increase the efficiency, and clearance effects. Additionally, it was also studied the impingement on the efficiency of the turbine caused by the inline guide block angle, reaching a maximum numerical efficiency of $42.4 \%$ for a $30^{\circ}$ block angle [20]. Ultimately, the effect on the efficiency and pressure loss of the angle between the guide and conversion blocks was determined, which showed that the variation of this angle had a light influence on the power of the first stage of 
the turbine, increasing the pressure loss at the expense of lowering the power at the second stage [21]. The optimal arc angle was found to be $105^{\circ}$, which allowed to increase the turbine efficiency up to $42.6 \%$.

Conversely, an experimental study developed by Chen et al., [22] on vertical axis Savonius turbines of $92 \mathrm{~mm}$ in diameter for in-pipe installation showed that a maximum mechanical power value of $88 \mathrm{~W}$ was reached by a 12-blade-hollow-type turbine with a pressure loss of $4.85 \mathrm{~m}$. Also, the investigation of Ma et al., [23] provided a theoretical, numerical, and experimental study on dragtype turbines, as well as a summary of all research activities of an inline hydroelectric generating system (IHGS) for 250 and $600 \mathrm{~mm}$ in diameter.

Besides, the experimental investigations of Hadi et al., [24] on Savonius turbines for water pipes showed that the twist angle of the turbine blades was helpful to increase the power coefficient of the turbine for flow rates under $8.16 \times 10^{-3} \mathrm{~m}^{3} / \mathrm{s}$. Although for higher flow rates, the power coefficient was greater without the use of twist angles [24]. Additionally, a similar study concluded that for the same Savonius turbine used in wastewater pipes of 3-inch in diameter, the optima blade overlap ratio was 0.3 , which generated $30.58 \mathrm{~W}$ of power output at a tip speed ratio of 0.79 [25]. Other numerical studies on the vortex shedding, flow topology, and the effects of walls of experimental rigs on lift and drag have been also carried out $[26,27]$.

In like manner, the studies of Payambarpour et al., [28] showed the investigations of a modified drag-type Savonius turbine of $92 \mathrm{~mm}$ in diameter for in-pipe installation. It was determined that a 5blade turbine was the optimal blade configuration for hydropower harnessing and smoothing out torque ripples. Similarly, a numerical and experimental study on the same turbine showed the effects of the clearance, flow rate variation, head loss, and performance, where it was concluded that the optimal performance was obtained at a rotational speed of $50 \mathrm{rad} / \mathrm{s}$ and with a $4 \mathrm{~mm}$ clearance, generating $55 \mathrm{~W}$ and $20 \mathrm{kPa}$ of pressure drop [29]. Lastly, an analytical, numerical, and experimental study was developed on the drag-type modified Savonius turbines, where a parametric study was realized determining the optimal geometric dimensions of the turbine and the deflector, which guides the flow for the increase of turbine efficiency [30].

Axial and propeller-type turbines can also be used for hydropower harnessing within pipes. For instance, contra-rotating axial turbines have been investigated by Ryosuke et al., [31] for a small turbine diameter of $70 \mathrm{~mm}$, for which a high numerical efficiency of $70.8 \%$ was reached. Shigemitsu et al., [32,33] performed a numerical and experimental analysis of a similar contra-rotating turbine of $60 \mathrm{~mm}$ in diameter, which showed a maximum turbine efficiency of 59\%, and the fluid dynamics effects of the rotors and the spokes which held the turbine in place inside the pipe. Finally, Nan et al., [34] studied the performance of an ultra-small modified contra-rotating turbine of $58 \mathrm{~mm}$ in diameter, which determined that lengthening the front and chamfering the rear hub of the turbine and having blades with variable thickness made velocity transitions smoother and increased the overall efficiency of the turbine up to $64.7 \%$, respectively.

Propeller-type turbines have been thoroughly investigated by Ramos et al., [35] providing theoretical and economic analysis for the viability of a cost-effective axial turbine for possible implementation in water supply systems, and the harnessing of flooding in urban areas using hydro turbines [36]. Similarly, Ramos et al., [37] have also researched small-sized propeller turbines for 85 and $100 \mathrm{~mm}$ in diameter, providing a design methodology for the turbine blades, and numerical and experimental studies, reporting a maximum turbine efficiency of approximately 64\% [38].

The investigations of Nishi et al., [39] provided a design methodology for an ultra-small axial turbine with guide blades, which utilized 2D and 3D flow analysis and particle image velocimetry (PIV) measurements that helped to improve the turbine efficiency up to $76.8 \%$. Moreover, a similar study was carried out to determine the fluid dynamic reasons for the increase in the turbine efficiency 
utilizing computational fluid dynamics (CFD) and experimental measurements, in which was found that the dampening of the tip leakage vortex near the hub at the blade outlet caused hydraulic losses [40]. Lastly, the study of Alexander et al., [41] made crucial contributions to the design, selection, and scaling of axial turbines for hydroelectric generation, which demonstrated that flat blades could be designed for manufacturing simplicity, and still being close enough to the ideal blade design.

Based on the bibliography, it was found that one of the most efficient turbines for in-pipe installation was the propeller-type axial turbine, reaching efficiencies up to $70 \%$, in comparison to less efficient turbines as the Darrieus spherical. Additionally, there is a lack of investigations for turbines less than $80 \mathrm{~mm}$ in diameter. Consequently, the objective of this study is to evaluate the fluid dynamic behavior of a lift-based propeller turbine for a $76.2 \mathrm{~mm}$ diameter pipe using computational fluid dynamics (CFD) for the prediction of pico-hydroelectric generation.

\section{Methodology}

\subsection{Governing Equations}

The $\kappa-\varepsilon$ turbulence model is one of the most used turbulence models at the industrial and research levels [42]. The $\kappa$ term represents the turbulence kinetic energy $\left[\mathrm{m}^{2} \mathrm{~s}^{-2}\right]$, and $\varepsilon$ is the turbulence eddy dissipation $\left[\mathrm{m}^{-2} \mathrm{~s}^{-3}\right]$. Then, Eq. (1) defines the equation of continuity, where $\rho$ is the density of water, $t$ is time, and $U_{j}$ represents the three spatial components of the fluid velocity $u, v, w$.

$$
\frac{\partial \rho}{\partial t}+\frac{\partial}{\partial x_{j}}\left(\rho U_{j}\right)=0
$$

Two momentum equations are defined by Eq. (2) and Eq. (3) in which $\kappa$ and $\varepsilon$ are related, where $C_{\varepsilon 1}, C_{\varepsilon 2}, \sigma_{\varepsilon}, \sigma_{k}$ are constants. $P_{k b}$ and $P_{\varepsilon b}$ represent the influence of buoyant forces [43].

$$
\begin{aligned}
& \frac{\partial(\rho k)}{\partial t}+\frac{\partial}{\partial x_{j}}\left(\rho U_{j} k\right)=\frac{\partial}{\partial x_{j}}\left[\left(\mu+\frac{\mu_{t}}{\sigma_{k}}\right) \frac{\partial k}{\partial x_{j}}\right]+P_{k}-\rho \varepsilon+P_{k b} \\
& \frac{\partial(\rho \varepsilon)}{\partial t}+\frac{\partial}{\partial x_{j}}\left(\rho U_{j} \varepsilon\right)=\frac{\partial}{\partial x_{j}}\left[\left(\mu+\frac{\mu_{t}}{\sigma_{\varepsilon}}\right) \frac{\partial \varepsilon}{\partial x_{j}}\right]+\frac{\varepsilon}{k}\left(C_{\varepsilon_{1}} P_{k}-C_{\varepsilon_{2}} \rho \varepsilon_{t}+C_{\varepsilon_{1}} P_{\varepsilon b}\right)
\end{aligned}
$$

The turbine torque $T$ is calculated using Eq. (4), where $S$ represents the surface of the rotating parts, $\vec{r}$ is the position vector, $\overline{\bar{\tau}}$ the total stress tensor (pressure and viscous stresses), $\hat{n}$ is a unit vector normal to the rotating surface, and $\hat{a}$ is a unit vector parallel to the axis of rotation [44].

$T=\left(\int_{S}[\vec{r} \times(\overline{\bar{\tau}} \cdot \hat{n})] d S\right) \cdot \hat{a}$

Eq. (5)-(7) define the dimensionless coefficients of head $C_{H}$, capacity $C_{Q}$, and power $C_{P}$, respectively. They relate the acceleration of gravity $\mathrm{g}\left[\mathrm{ms}^{-2}\right]$, hydraulic head $H[\mathrm{~m}]$, angular velocity $\omega\left[\mathrm{rad} \mathrm{s} \mathrm{s}^{-1}\right]$, the characteristic diameter $D[\mathrm{~m}]$, the density of the fluid $\rho\left[\mathrm{kg} \mathrm{m}^{-3}\right]$, the flow rate $Q\left[\mathrm{~m}^{3} \mathrm{~s}^{-1}\right]$, and the mechanical power $P_{\text {mech }}=\omega T[45]$. 
$C_{H}=\frac{g H}{\omega^{2} D^{2}}$

$C_{Q}=\frac{Q}{\omega D^{3}}$

$C_{P}=\frac{P_{m e c h}}{\rho \omega^{3} D^{5}}$

The hydraulic efficiency of a turbine is defined by Eq. (8), where ratios of the mechanical power produced by the turbine, the hydraulic energy available in the streamflow, and the dimensionless coefficients are shown [45].

$\eta_{H}=\frac{P_{\text {mech }}}{\rho g H Q}=\frac{C_{P}}{C_{Q} C_{H}}$

The Eq. (9) defines the pressure drop $\Delta P[\mathrm{~m}]$, where $P_{1}$ and $P_{2}$ are the inlet and outlet pressures.

$\Delta P=\frac{P_{2}-P_{1}}{g \rho}$

\subsection{Geometry of Turbines}

\subsubsection{Geometry of the lift-based propeller-type turbine}

The propeller-type turbine geometry was based on the investigation of Ramos et al., [37], which showed the blade design and the study of a $100 \mathrm{~mm}$ diameter turbine. Ramos et al., [37] assumed a free-vortex flow at the outlet of the blade for the turbine design, which satisfies the theory of radial equilibrium [46]. In other words, the velocity radial components are not present, leading to a constant axial velocity through the turbine. Figure $1(\mathrm{a})$ shows the general dimensions of the turbine geometry which were scaled down by a factor of 0.76 for the present study. Figure 1 (b) presents an isometric view of the turbine.

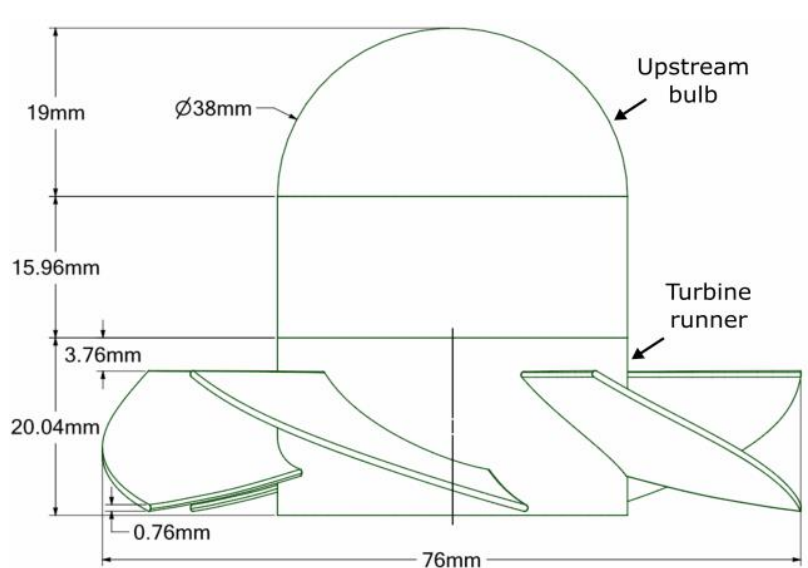

(a)

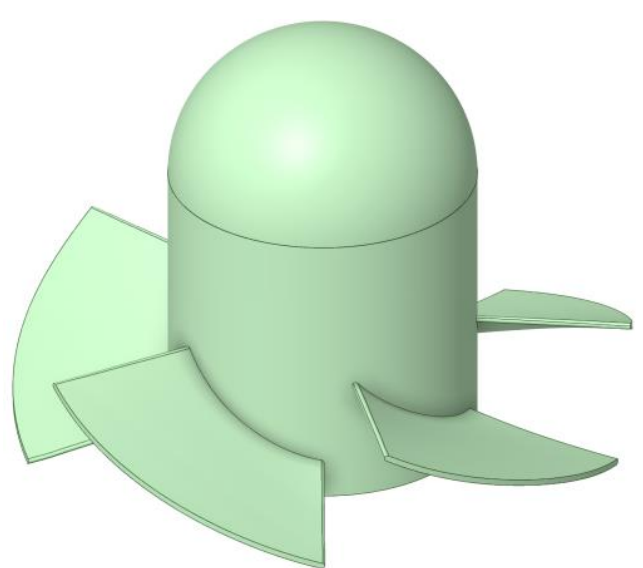

(b)

Fig. 1. Propeller-type turbine model; (a) General dimensions, (b) Three-dimensional view 


\subsection{CFD Simulation Setup}

\subsubsection{Control volumes}

Figure 2 presents the computational domains for the propeller turbine. The stationary domains represent the $76.2 \mathrm{~mm}$ diameter pipe, which has two elbows of $45^{\circ}$ each. The rotational domain containing the propeller turbine was located at 8 turbine diameters $(D=76 \mathrm{~mm})$ from the inlet and outlet. The clearance between the tip of the blades and the pipe wall was $0.1 \mathrm{~mm}$.

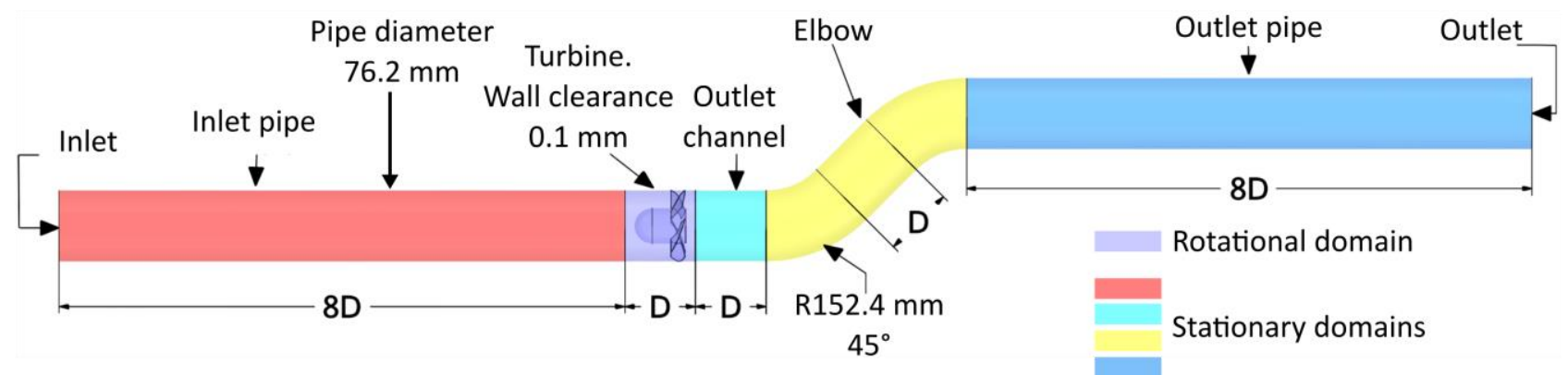

Fig. 2. Computational domains for the numerical simulation of the propeller turbine

\subsubsection{Mesh independence study}

The mesh independence study used the hydraulic efficiency $\eta_{H}$ as the output parameter for both turbines, because it contains the main fluid dynamic variables, as stated in Eq. (8). Figure 3 presents the mesh independence study result of the propeller turbine, which used 5 refinement mesh points. The optimum number of elements for the simulation was 2817590 with an error of $0.1167 \%$ compared to the next refinement point.

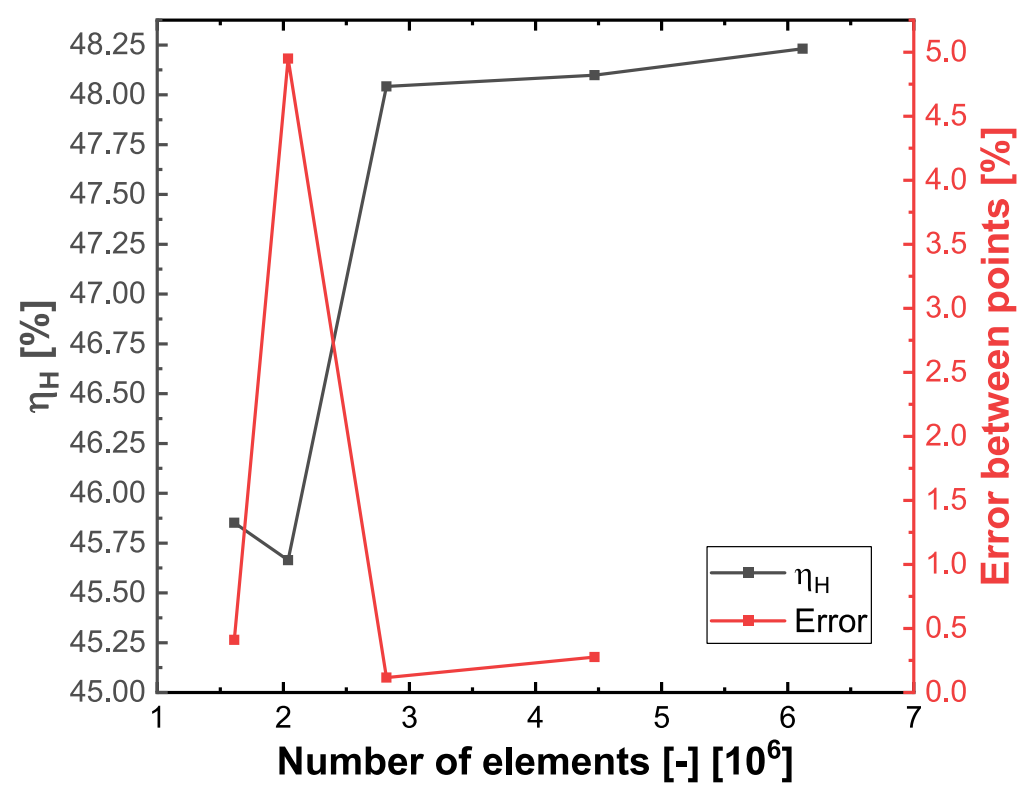

Fig. 3. Mesh independence study result of the propeller turbine

The mesh and the inflation layers were generated by Mesh of ANSYS 2020 R1. The inflation layers for the turbine blades and the pipe wall used a desired $y^{+}=30$, a characteristic velocity $U=3 \mathrm{~m} / \mathrm{s}$, and characteristic lengths of 0.04144 and $0.076 \mathrm{~m}$, respectively. The computed distance to the first cell of the mesh $y_{H}$ for the blades and pipe wall were $2 \times 10^{-4}$ and $3.64 \times 10^{-4} \mathrm{~m}$, respectively. Figure 4(a) shows a cross-sectional view of the tetrahedrons-based mesh of the control volumes of the 
propeller turbine. Figure 4(b) shows the details of the blade inflation generation, which has 8 layers and a growth rate of 1.2, and the pipe wall was generated with 6 layers with a growth rate of 1.1. Quality-wise, the mesh has average quality values of orthogonal quality with a value of 0.766 , skewness of 0.233 , and an aspect ratio of 2.226 , all of which are within the allowed quality thresholds for the CFD solver [43].

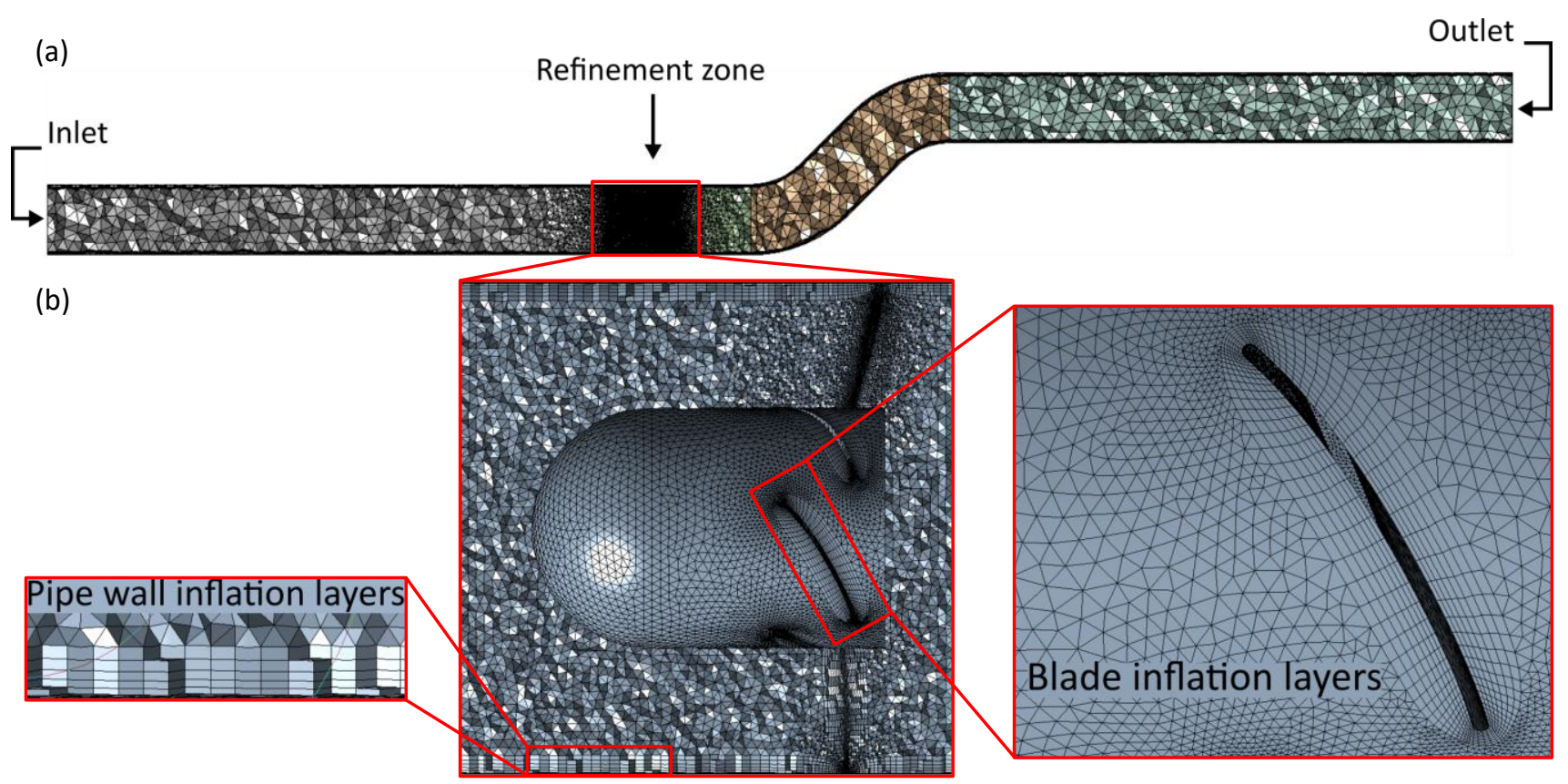

Fig. 4. Details of the propeller turbine computational mesh

\subsubsection{Boundary conditions and parametric study}

The CFD simulations were executed using the fluid dynamics commercial code CFX of ANSYS 2020 R1. The simulations used a stationary analysis, the RANS Standard $k-\varepsilon$ turbulence model, a frozen rotor approach, and water at $25^{\circ} \mathrm{C}$ without heat transfer. Figure 5 defines the boundary conditions applied to the numerical simulation shown in green color. Figure $5(\mathrm{a})$ shows the inlet mass flow $\dot{m}$ boundary condition with a turbulence intensity of $I=5 \%$, the relative pressure boundary condition at the outlet, and the no-slip condition applied to the pipe wall. Figure $5(\mathrm{~b})$ shows the fluid-solid interface applied to the turbine blades and hub, and the fluid-fluid interface applied to the shroud, respectively. 
(a)

Outlet relative pressure $\mathrm{P}=\mathbf{0} \mathrm{Pa}$

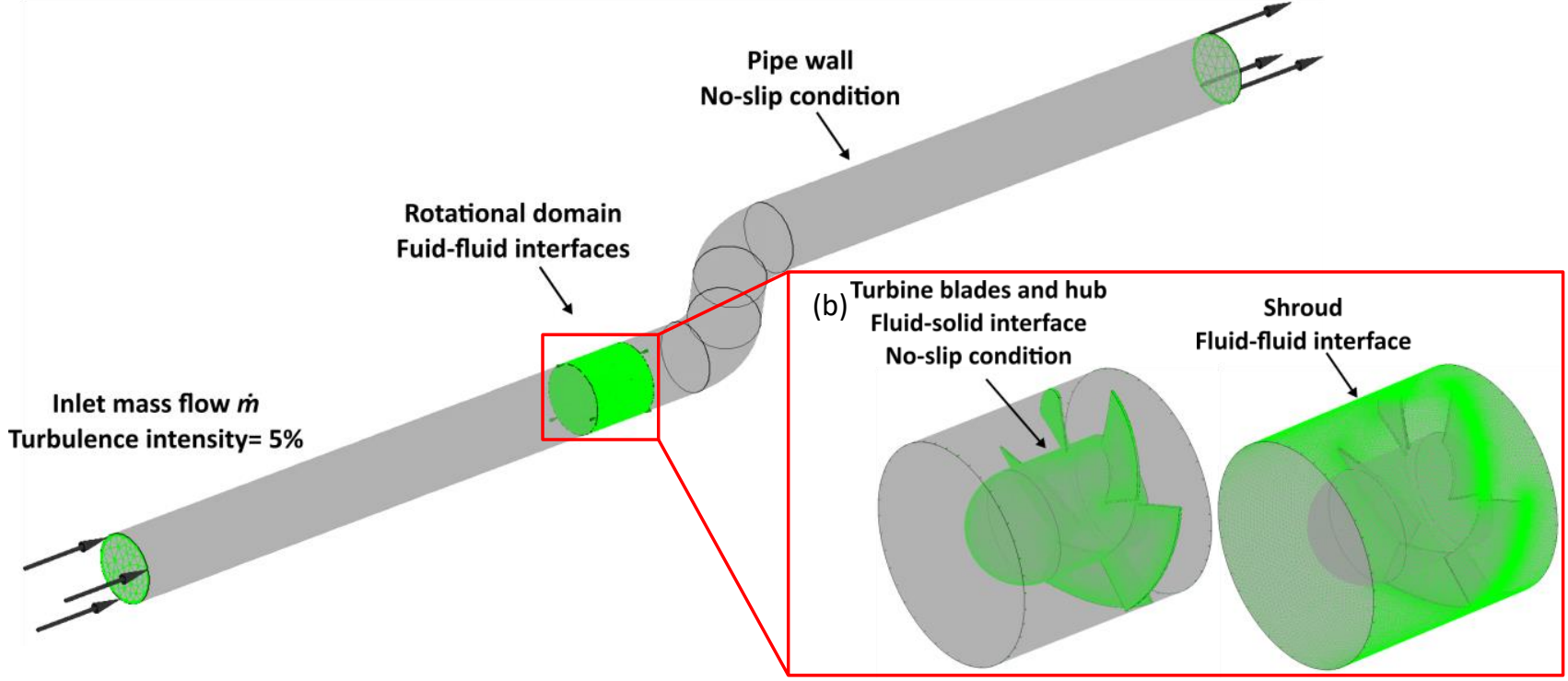

Fig. 5. Simulation boundary conditions; (a) Inlet and outlet boundary conditions of the stationary domain (b) Rotational domain interfaces

The parametric study used as the input parameters the mass flow rate varied between $(4.57 \leq$ $\dot{m} \leq 16.62) \mathrm{kg} / \mathrm{s}$ with steps of $1.38 \mathrm{~kg} / \mathrm{s}$, and the angular velocity using an initial value of $50 \mathrm{rpm}$ and then varied between $(50 \leq N \leq 2750) \mathrm{rpm}$ with steps of $250 \mathrm{rpm}$. Then, for every value of $N$, the mass flow rate $\dot{m}$ was varied within its whole range. The CFD solver reported as output parameters the torque $T[\mathrm{Nm}]$ of the turbine, and the pressure difference $\Delta P$ between the inlet and outlet walls of the pipe.

\section{Results}

\subsection{Parametric Study Results}

This subsection presents the relation between parameters like the head $H[\mathrm{~m}]$, the mechanical power $P_{\text {mech }}[W]$, and the hydraulic efficiency [\%], with the volumetric flow rate $Q\left[\mathrm{~m}^{3} / \mathrm{s}\right]$ for every variation of the angular velocity $N[\mathrm{rpm}]$.

Figure 6(a) shows the optimum range of $Q$ for every variation of $N$, which suggests that as angular velocity increases, the range of the flow rate $Q$ reduces progressively. In other words, for combinations of high values of $N$ and low values of $Q$, the turbine does not extract hydraulic energy, but rather transferring energy, turning into a pump behavior. Figure $6(\mathrm{~b})$ presents various operational points of the angular velocity $N$, where $H$ is plotted against $Q$. The graph shows that the relation between $H$ and $Q$ is proportional, which indicates that the turbine transforms more potential energy as the flow rate increases. Nonetheless, when $N$ increases, the range of operation of $H$ decreases, meaning that it is also an inverse relation. 


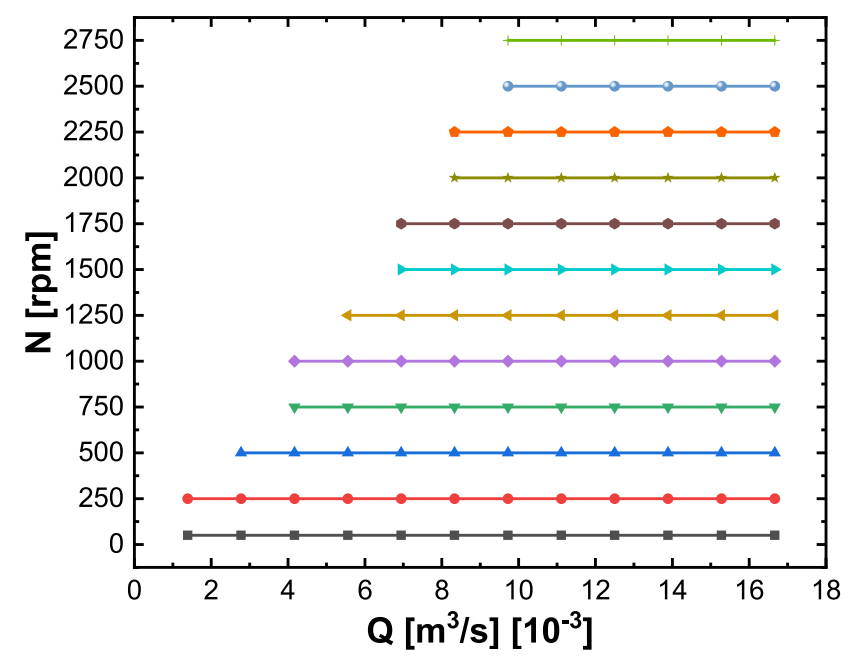

(a)

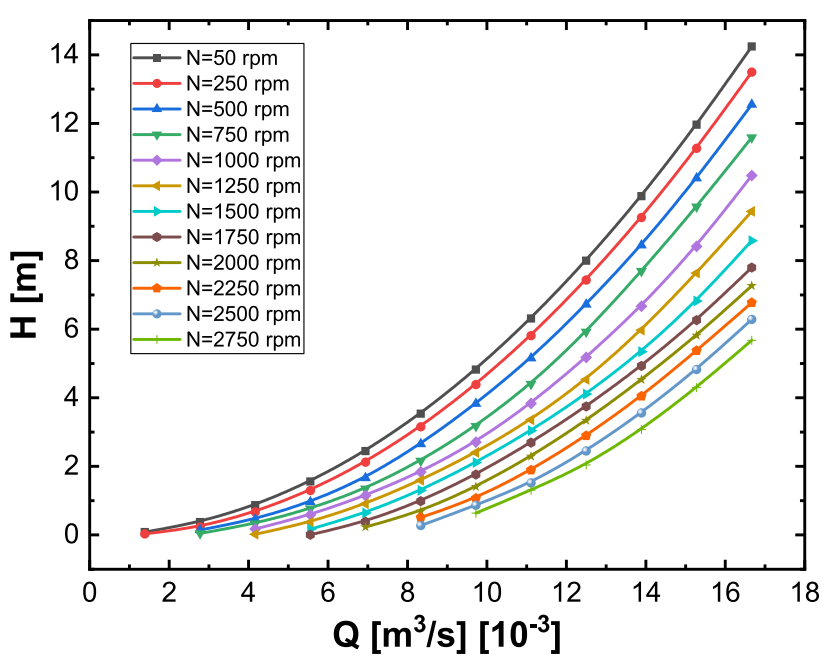

(b)

Fig. 6. (a) flow rate $Q$ vs. angular velocity $N$, (b) flow rate $Q$ vs. head $H$

Figure 7(a) presents the relation between $Q$ and mechanical power $P_{\text {mech }}$ for an angular velocity range of $(50 \leq N \leq 1250) \mathrm{rpm}$. The curves indicate that $Q$ and $H$ are proportional, but for low values of $\omega$, as $N=50$ and $250 \mathrm{rpm}$, the influence of $Q$ on the increment of $P_{\text {mech }}$ is not as great as other values. For example, values of $N>250 \mathrm{rpm}$ result in curves of $P_{\text {mech }}$ with a greater slope. Figure $7(\mathrm{~b})$ shows the relation of the flow rate and the head for an angular velocity range of $(1500 \leq N \leq 2750) \mathrm{rpm}$. The graph shows that for a range of $N$ between 1500 and $2000 \mathrm{rpm}$, $P_{\text {mech }}$ is higher for low values of $Q$ in comparison to greater values of $N$. Additionally, all the curves of $P_{\text {mech }}$ approximate to a range between 570 and $621 \mathrm{~W}$, where the maximum value of $P_{\text {mech }}$ reached is $621 W$ at $N=2250 \mathrm{rpm}$, and $Q=16.7 \times 10^{-3} \mathrm{~m}^{3} / \mathrm{s}$.

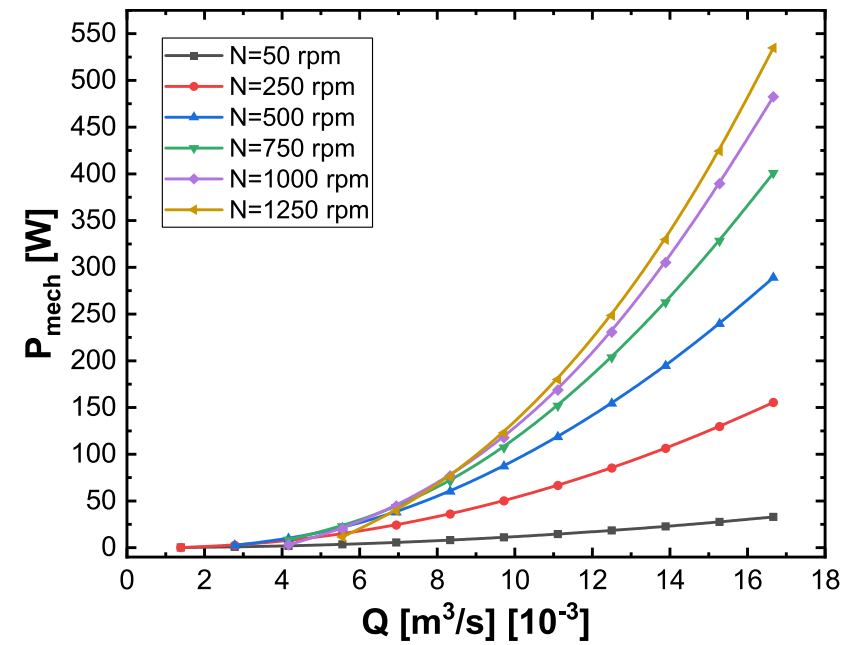

(a)

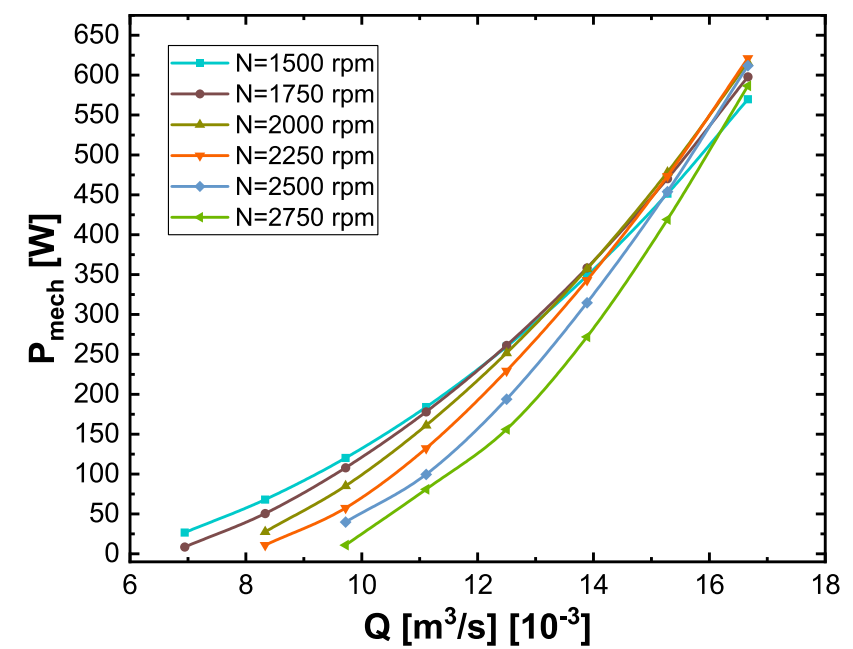

(b)

Fig. 7. Flow rate $Q$ vs. mechanical power $P_{\text {mech }}$ (a) angular velocity range for ( $\left.50 \leq N \leq 1250\right) \mathrm{rpm}$, (b) angular velocity range for $(1500 \leq N \leq 2750) \mathrm{rpm}$

Figure $8(\mathrm{a})$ and Figure $8(\mathrm{~b})$ show the relation of $Q$ vs. $\eta_{H}$ for an angular velocity range of $(1000 \leq N \leq 1750) \mathrm{rpm}$ and $(2000 \leq N \leq 2750) \mathrm{rpm}$, respectively. In the graphs, there are inflection points for every curve of $\eta_{H}$, which represent the maximum and optimal values of the turbine performance, and then they decrease as $Q$ rises. The maximum hydraulic efficiency reached by the turbine is $\eta_{H}=64.46 \%$ for an angular velocity $N=1750 \mathrm{rpm}$, and a flow rate of $Q=9.7 \times 10$ ${ }^{3} \mathrm{~m}^{3} / \mathrm{s}$. The curves of $\eta_{H}$ for an angular velocity range of (50 $\left.\leq N \leq 750\right) \mathrm{rpm}$ are not reported on 
a graph, because $\eta_{H}$ quickly decreases with small variations of $Q$, hence representing a non-optimal range of operation in terms of turbine performance.

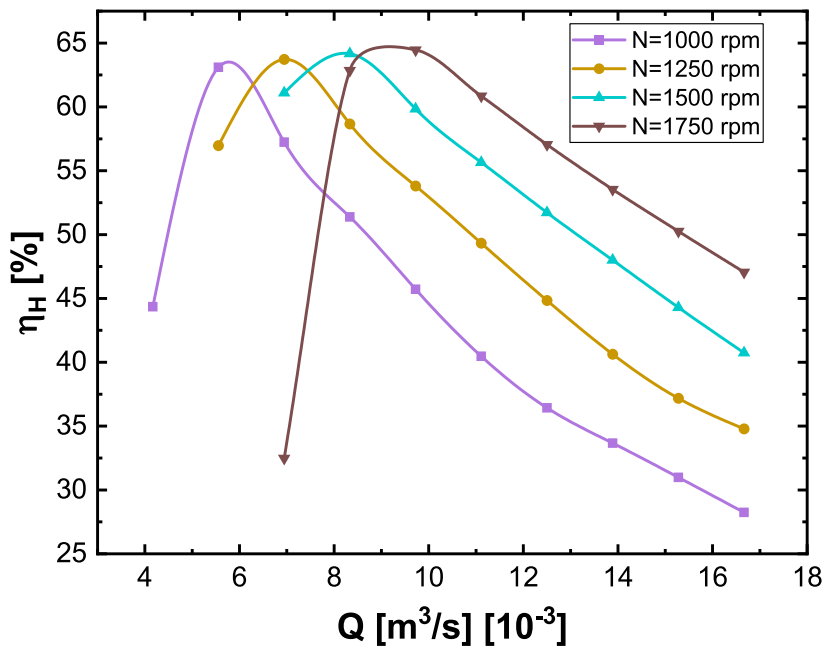

(a)

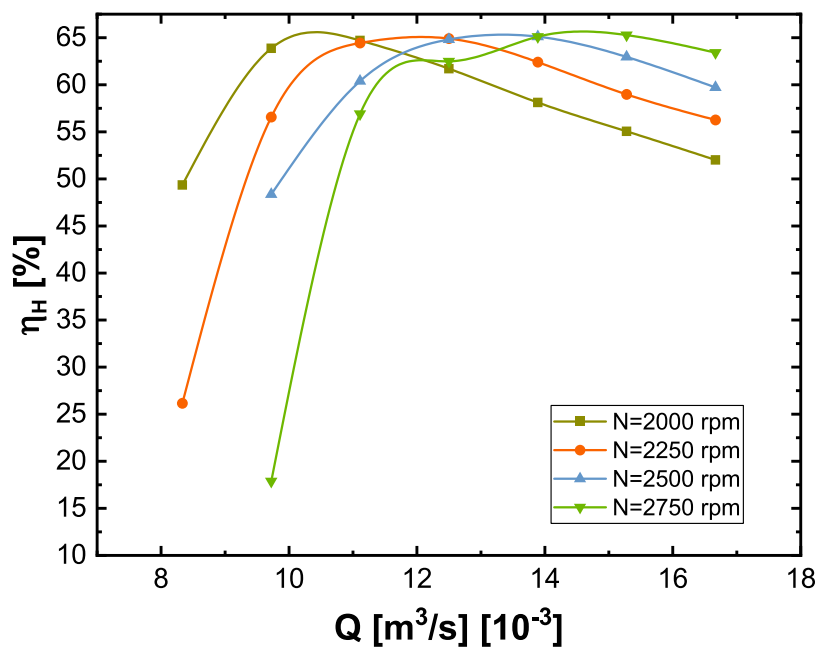

(b)

Fig. 8. Relation between the flow rate $Q$ and the hydraulic efficiency $\eta_{H}$; (a) ( $50 \leq N \leq 750$ ) $r p m$, (b) $(1000 \leq N \leq 1750) \mathrm{rpm}$, (c) $(2000 \leq N \leq 2750) \mathrm{rpm}$

Figure 9 presents the best efficiency point BEP for the propeller turbine, where the curves of the hydraulic efficiency $\eta_{H}$, the head $H$, the mechanical power $P_{\text {mech }}$ are plotted against the flow rate $Q$. The BEP is located at the maximum obtained value of $\eta_{H}$ defined by a dotted green color line, which indicates the optimum operating parameters for $Q, H$, and $P_{\text {mech }}$ at an angular velocity of $N=1750$ rpm.

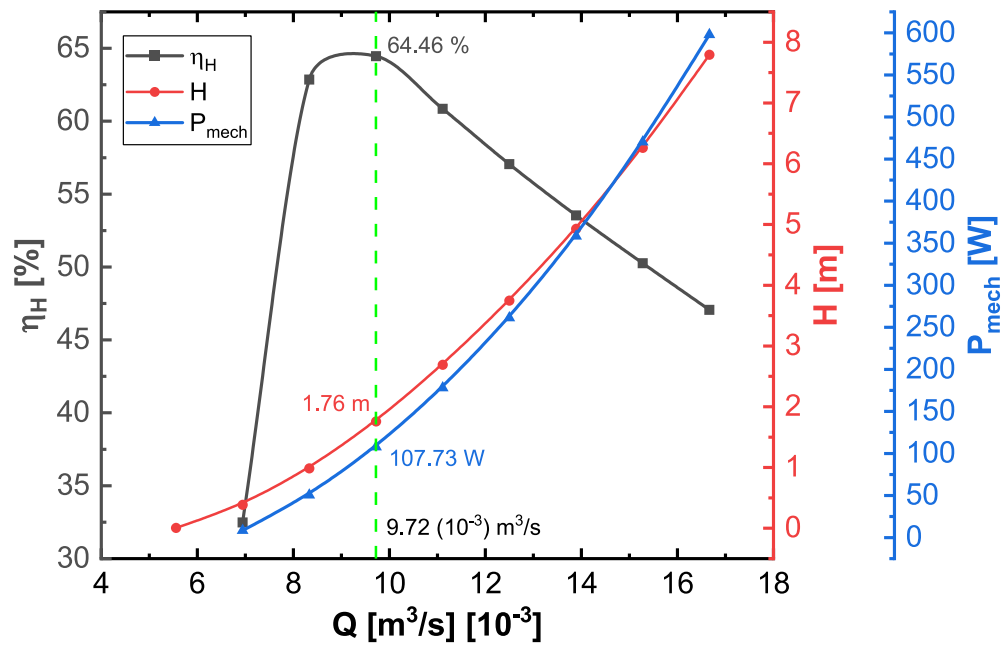

Fig. 9. Best efficiency point BEP of the propeller turbine for an angular velocity of $N=1750 \mathrm{rpm}$

\subsection{CFD Contours}

\subsubsection{Contours of dimensionless distance $y^{+}$}

This subsection shows the contour of the dimensionless distance $y^{+}$of the first cell of the mesh applied to the wall of the turbine. Figure 10(a) shows a frontal view of the hub zone and the pressure surfaces of the blade. It is possible to observe the values of $y^{+}$quantitatively and qualitatively in a range of $14 \leq y^{+} \leq 140$, which indicates that the surfaces of the turbine are approximately within 
the desired range of $30 \leq y^{+} \leq 300$. Figure $10(\mathrm{~b})$ shows a lateral view of the turbine, in which zones of rough $y^{+}$contour transitions are indicated by red ovals. This irregularities on the contour are due to the differences in the refinement of the tetrahedron and hexahedron mesh elements. It can also be observed that there some zones with high $y^{+}$values, which are out of the desired values of $y^{+}$, however, the zones of interest are the surfaces of the turbine blades since they produce the turbine torque. Figure 10(c) presents an isometric view that allows showing the suction surfaces of the blades, and the rear zone of the hub. The values of $y^{+}$of the suction surfaces range approximately between $88 \leq y^{+} \leq 93$, which are within the desired range of the dimensionless distance.

\subsubsection{Pressure and velocity contours of the control volumes}

The contours presented in this subsection are at the BEP point. They are located on the $X Z$ plane at $Y / D=0.5$, and the flow direction is in the positive $X$ direction. Figure 11(a) and Figure 11(b) present the pressure and velocity contours of the pipe (stationary domain) near the turbine, respectively. The contours show vertical lines which represent the interface of the rotational domain. For both contours, a zone of high pressure, and low velocity is denoted with dotted lines upstream the turbine, which is generated by the reduction of the fluid momentum when approaches the hub wall. Similarly, a wake zone downstream of the turbine is highlighted, where zones of low pressures and high velocities are generated by the turbulence due to the presence of the turbine.
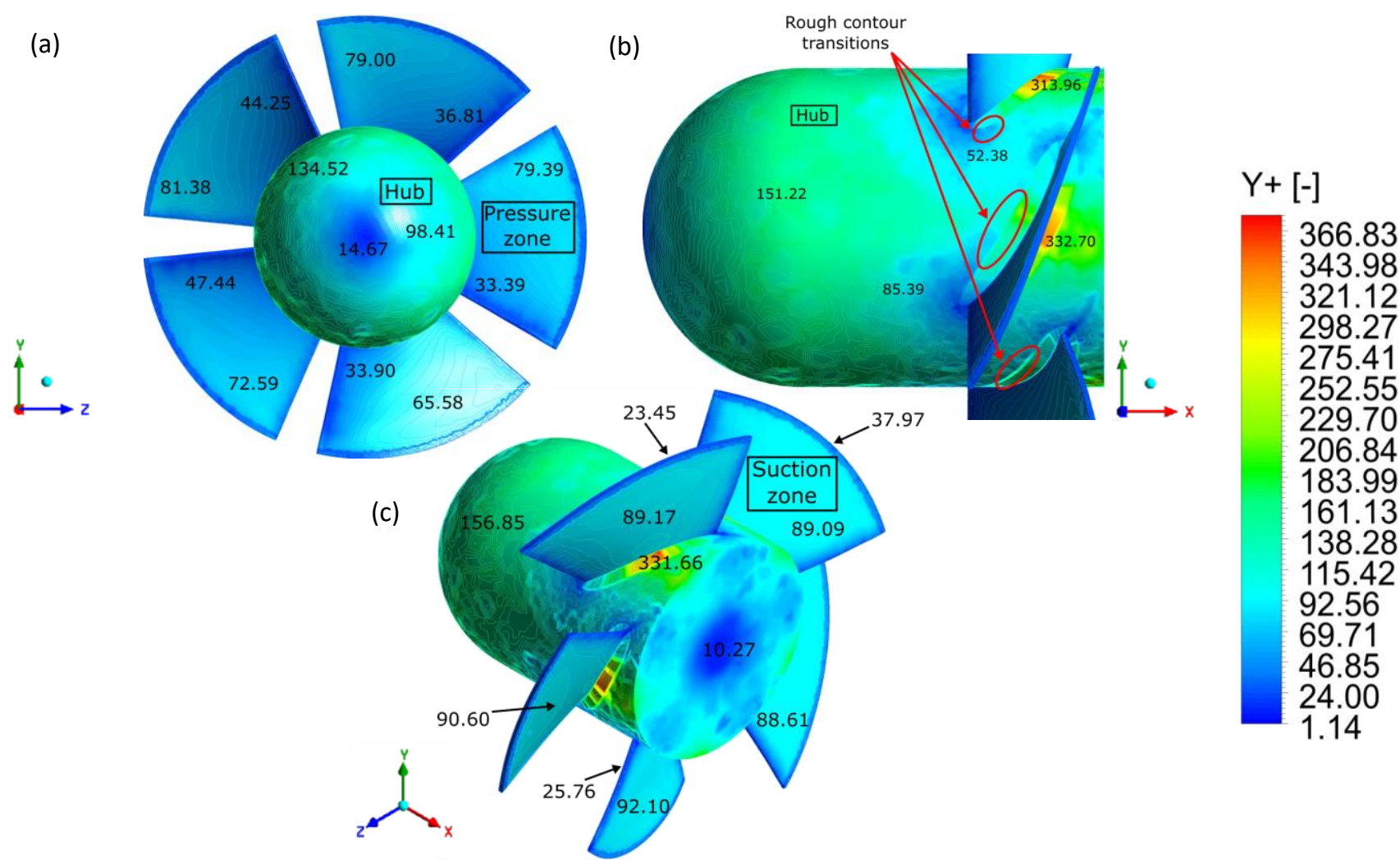

Fig. 10. Contours of $y^{+}$of the turbine walls at the best efficiency point BEP; (a) frontal view of the hub and the pressure surfaces of the turbine blades, (b) Detailed lateral view of the turbine hub, (c) isometric view showing the suction surfaces of the turbine blades 


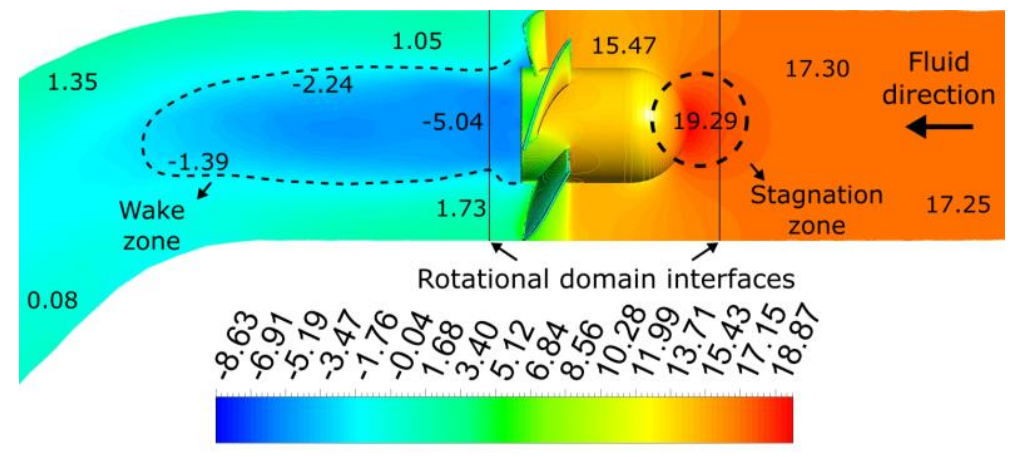

(a)

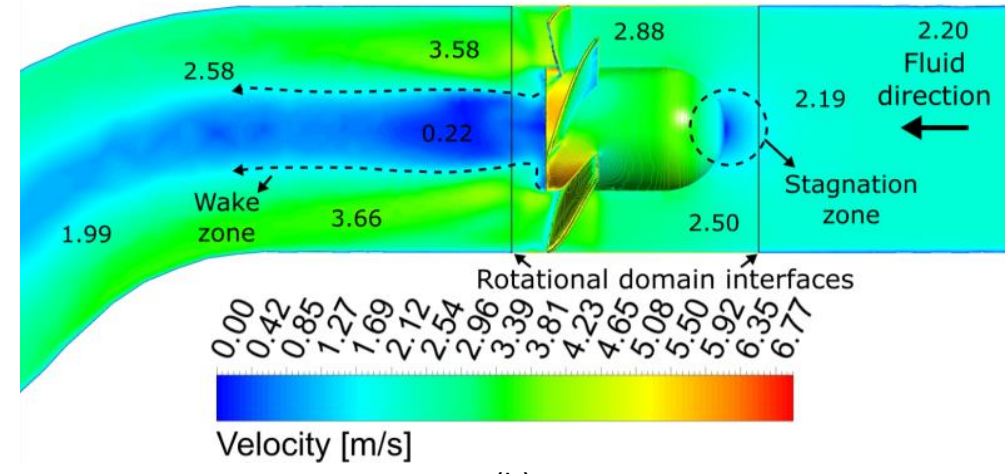

(b)

Fig. 11. CFD contours at the best efficiency point BEP on the $X Z$ plane located at $Y / D=0.5$; (a) top view of the pressure contour, (b) top view of the velocity contour

\subsubsection{Pressure and velocity contours of the turbine walls}

Figure 12(a) and Figure 12(b) present the pressure and velocity contours at the BEP applied to the walls of the propeller turbine, respectively, where the fluid follows the $X$ positive axis direction, and the direction of rotation of the turbine is given. From the contours, the fluid dynamic behavior can be validated based on the inverse relation of the pressure and velocity of the fluid. In other words, the pressure magnitude on the pressure zone of the blades, Figure 12(a), is higher as the fluid gets closer to the hub, or as the radial direction decreases. The same applies to the suction zone of the blade, where the pressure is lower. Figure 12(b) shows the velocity contour and direction vectors, in which the inverse relation of the pressure and velocity can be seen. Such behavior is because the tangential velocity is proportional to the radial direction $r$, resulting in high fluid velocities as it approaches the blade tips. Ultimately, the suction zone has higher values of velocity due to the shape of the blade. 
(a)
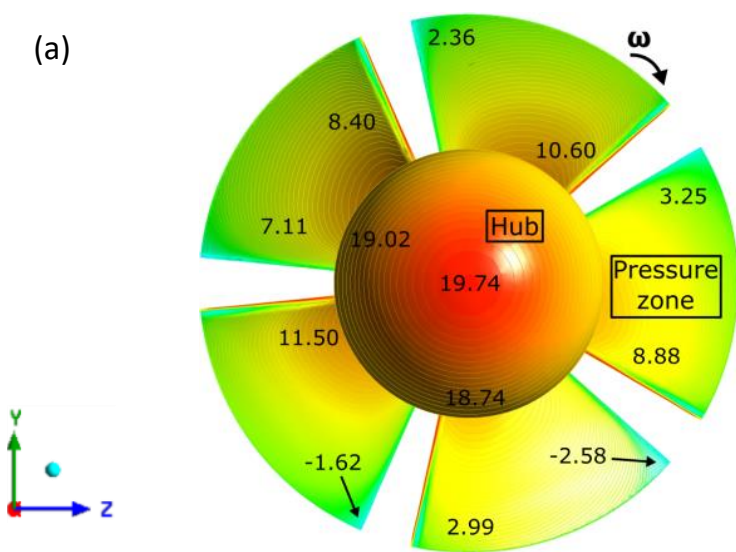

(b)

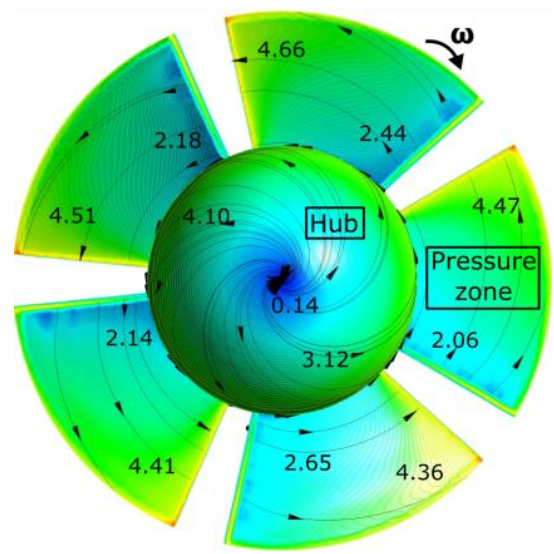

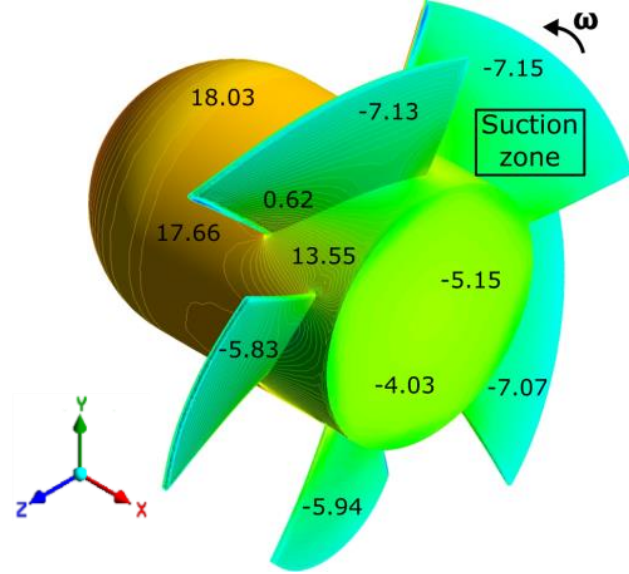

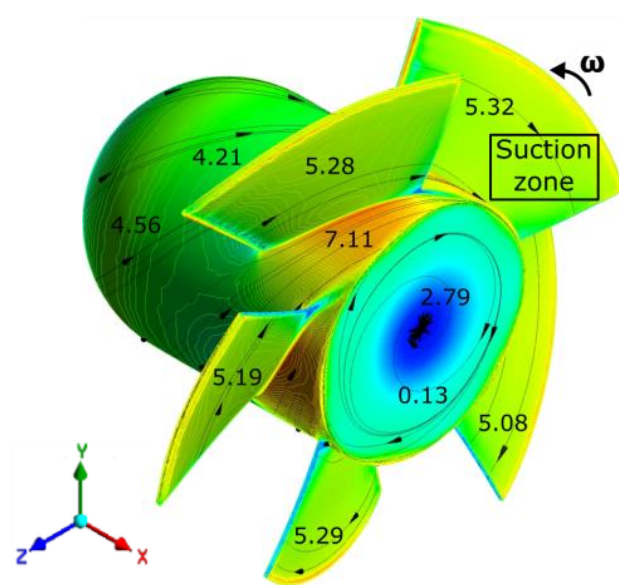

Pressure $[\mathrm{kPa}]$

18.98

14.87

10.76

6.65

2.54

$-1.57$

$-5.69$

$-9.80$

$-13.91$

$-18.02$

$-22.13$

$-26.24$

$-30.35$

$-34.46$

$-38.57$

$-42.68$

$-46.79$

Velocity $[\mathrm{m} / \mathrm{s}]$

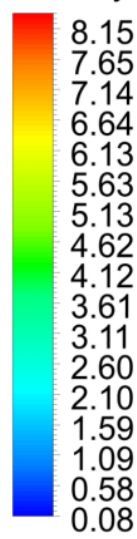

Fig. 12. CFD contours at the best efficiency point BEP applied to the walls of the propeller turbine; (a) frontal and isometric view of pressure contour, (b) frontal and isometric view of velocity contour

\section{Conclusions}

A three-dimensional model of a propeller turbine for in-pipe installation, available in the bibliography, is modeled for a pipe of $76.2 \mathrm{~mm}$ in diameter. A parametric study to determine the fluid dynamic characteristic curves of the turbine is carried out. As a result, the best efficiency point for the turbine operation is found for the maximum hydraulic efficiency of $64.46 \%$, at a flow rate of $9.72 \times 10^{-3} \mathrm{~m}^{3} / \mathrm{s}$, a head drops of $1.76 \mathrm{~m}$, and mechanical power of $107.83 \mathrm{~W}$. This result is relevant due to the lack of numerical investigations for in-pipe turbine applications less than $80 \mathrm{~mm}$ in diameter. Therefore, the results of this work can be used as a reference for future experimental or numerical studies on the subject.

The obtained maximum hydraulic efficiency of the propeller turbine of $64.46 \%$ with a diameter of $76 \mathrm{~mm}$ is higher than the experimental hydraulic efficiency of the reference results by Samora et al., [38], which reports an efficiency of $63.75 \%$ for a turbine with $85 \mathrm{~mm}$ in diameter. On one hand, this indicates similarities in the results, but on the other hand, is contra-productive, because the predictions that the affinity laws of turbomachines provide suggest the contrary. This could be attributed to the simplifications with the shaft of the turbine, and no wall roughness.

Future work is needed on the transient simulation of this kind of turbine application, taking into account the shaft of the turbine and the wall roughness of the turbine and pipe walls to determine in a more detailed manner the fluid dynamic behavior of the fluid. Also, the determination of costbenefit based on the turbine diameter for applications within pipes would be of great value, since the mechanical power and hydraulic efficiency decrease as the turbine diameter is reduced. 


\section{Acknowledgment}

This study was supported by the investigation line of Advanced Computing and Digital Design -CADD - from the Instituto Tecnológico Metropolitano, providing the workstation for the numerical simulations.

\section{References}

[1] Paish, Oliver. "Small hydro power: technology and current status." Renewable and Sustainable Energy Reviews 6, no. 6 (2002): 537-556. https://doi.org/10.1016/S1364-0321(02)00006-0

[2] Carravetta, Armando, Oreste Fecarotta, Helena M. Ramos, Maria Mello, Juan Antonio Rodriguez-Diaz, Jorge Garcia Morillo, Kemi Adeyeye, Paul Coughlan, John Gallagher, and Aonghus McNabola. "Reducing the Energy Dependency of Water Networks in Irrigation, Public Drinking Water, and Process Industry: REDAWN Project." In Multidisciplinary Digital Publishing Institute Proceedings, vol. 2, no. 11, p. 681. 2018. https://doi.org/10.3390/proceedings2110681

[3] Morani, Maria Cristina, Armando Carravetta, Giuseppe Del Giudice, Aonghus McNabola, and Oreste Fecarotta. "A comparison of energy recovery by PATs against direct variable speed pumping in water distribution networks." Fluids 3, no. 2 (2018): 41. https://doi.org/10.3390/fluids3020041

[4] Fayzul, M., M. Fayzul K. Pasha, Matthew Weathers, and Brennan Smith. "Investigating Energy Flow in Water-Energy Storage for Hydropower Generation in Water Distribution Systems." Water Resources Management (2020): 1-14.

[5] Dequesene, Jeanne, Anar Valimahamed, and Eric Bréjoux. Observatoire des services publics d'eau et d'assainissement. Panorama des services et de leur performance en 2016 (2016).

[6] Dequesene, Jeanne, Anar Valimahamed, and Eric Bréjoux. Observatoire des services publics d'eau et d'assainissement. Panorama des services et de leur performance en 2017 (2017).

[7] Ramos, H. M., M. Mello, and P. K. De. "Clean power in water supply systems as a sustainable solution: from planning to practical implementation." Water Science and Technology: Water Supply 10, no. 1 (2010): 39-49. https://doi.org/10.2166/ws.2010.720

[8] Sammartano, Vincenzo, Costanza Aricò, Armando Carravetta, Oreste Fecarotta, and Tullio Tucciarelli. "BankiMichell optimal design by computational fluid dynamics testing and hydrodynamic analysis." Energies 6, no. 5 (2013): 2362-2385. https://doi.org/10.3390/en6052362

[9] Saoutieff, Elise, Pierre Gasnier, Sébastien Boisseau, Javier Ojer-Aranguren, and Isabelle Rodot. "Performances of a $\mathrm{cm}$-scale water flow energy harvester in real environment for autonomous flowmeters." In Journal of Physics: Conference Series, vol. 1407, no. 1, p. 012074. IOP Publishing, 2019. https://doi.org/10.1088/1742$6596 / 1407 / 1 / 012074$

[10] Schlabach, Roderic A., Mark Rydell Cosby, Edward J. Kurth, Igor Palley, and Greg Smith. "In-pipe hydro-electric power system and turbine." U.S. Patent 7,959,411, issued June 14, 2011.

[11] Lucid Energy. "Lucidpipe Power System Case Study." Lucid Energy, Inc., 2013.

[12] Lucid Energy. "Lucidpipe Power System Case Study." Lucid Energy, Inc., 2016.

[13] Lee, Chang-Ryeol, Na-Yongkim, and Bong-Hwan Kim. "CFD analysis of a ducted spherical helical turbine for microhydropower." International Journal of Mechanical and Production Engineering Research and Development (IJMPERD) 10, no. 1 (2020): 237-248.

[14] Bachant, Peter, and Martin Wosnik. "Experimental investigation of helical cross-flow axis hydrokinetic turbines, including effects of waves and turbulence." In Fluids Engineering Division Summer Meeting, vol. 44403, pp. 18951906. 2011. https://doi.org/10.1115/AJK2011-07020

[15] Oladosu, Temidayo Lekan, and Olufemi Adebola Koya. "Numerical analysis of lift-based in-pipe turbine for predicting hydropower harnessing potential in selected water distribution networks for waterlines optimization." Engineering Science and Technology, An International Journal 21, no. 4 (2018): 672-678. https://doi.org/10.1016/i.jestch.2018.05.016

[16] Yeo, Honggu, Woochan Seok, Soyong Shin, Young Cheol Huh, Byung Chang Jung, Cheol-Soo Myung, and Shin Hyung Rhee. "Computational analysis of the performance of a vertical axis turbine in a water pipe." Energies 12, no. 20 (2019): 3998. https://doi.org/10.3390/en12203998

[17] Yang, Wei, Yimin Hou, Huiting Jia, Benqing Liu, and Ruofu Xiao. "Lift-type and drag-type hydro turbine with vertical axis for power generation from water pipelines." Energy 188 (2019): 116070. https://doi.org/10.1016/i.energy.2019.116070

[18] Langroudi, A. Tahadjodi, F. Zare Afifi, A. Heyrani Nobari, and A. F. Najafi. "Modeling and numerical investigation on multi-objective design improvement of a novel cross-flow lift-based turbine for in-pipe hydro energy harvesting applications." Energy Conversion and Management $203 \quad$ (2020): 112233. https://doi.org/10.1016/i.enconman.2019.112233 
[19] Jiyun, Du, Yang Hongxing, Shen Zhicheng, and Guo Xiaodong. "Development of an inline vertical cross-flow turbine for hydropower harvesting in urban water supply pipes." Renewable Energy 127 (2018): 386-397. https://doi.org/10.1016/j.renene.2018.04.070

[20] Du, Jiyun, Zhicheng Shen, and Hongxing Yang. "Effects of different block designs on the performance of inline crossflow turbines in urban water mains." Applied Energy 228 (2018): 97-107. https://doi.org/10.1016/j.apenergy.2018.06.079

[21] Jiyun, Du, Shen Zhicheng, and Yang Hongxing. "Numerical study on the impact of runner inlet arc angle on the performance of inline cross-flow turbine used in urban water mains." Energy 158 (2018): $228-237$. https://doi.org/10.1016/i.energy.2018.06.033

[22] Chen, Jian, H. X. Yang, C. P. Liu, C. H. Lau, and M. Lo. "A novel vertical axis water turbine for power generation from water pipelines." Energy 54 (2013): 184-193. https://doi.org/10.1016/i.energy.2013.01.064

[23] Ma, Tao, Hongxing Yang, Xiaodong Guo, Chengzhi Lou, Zhicheng Shen, Jian Chen, and Jiyun Du. "Development of inline hydroelectric generation system from municipal water pipelines." Energy 144 (2018): 535-548. https://doi.org/10.1016/i.energy.2017.11.113

[24] Hadi, Syamsul, Muhammad Sidiq, Dhimas Cahyo Anindito, Ari Prasetyo, Dominicus Danardono Dwi Prija Tjahjana, and Rintis Hadiani. "Experimental study of the effects of blade twist on the performance of Savonius water turbine in water pipe." Journal of Advanced Research in Fluid Mechanics and Thermal Sciences 57, no. 2 (2019): 202-207.

[25] Hadi, Syamsul, Hasnul Khuluqi, Dandun Mahesa Prabowoputra, Ari Prasetyo, Dominicus Danardono Dwi Prija Tjahjana, and Ahmad Farkhan. "Performance of savonius horizontal axis water turbine in free flow vertical pipe as effect of blade overlap." Journal of Advanced Research in Fluid Mechanics and Thermal Sciences 58, no. 2 (2019): 219-223.

[26] Ibrahim, Che Intan Hartini Che, and Aslam Abdullah. "Flow Topology around Low Reynolds Number Airfoils with Vortex Shedding." CFD Letters 12, no. 12 (2020): 85-103. https://doi.org/10.37934/cfdl.12.12.85103

[27] Abobaker, Mostafa, Abdulhafid M. Elfaghi, and Sogair Addeep. "Numerical Study of Wind-Tunnel Wall Effects on Lift and Drag Characteristics of NACA 0012 Airfoil." CFD Letters 12, no. 11 (2020): 72-82. https://doi.org/10.37934/cfdl.12.11.7282

[28] Payambarpour, S. Abdolkarim, Amir F. Najafi, and Franco Magagnato. "Investigation of Blade Number Effect on Hydraulic Performance of In-Pipe Hydro Savonius Turbine." International Journal of Rotating Machinery 2019 (2019). https://doi.org/10.1155/2019/8394191

[29] Payambarpour, S. Abdolkarim, and Amir F. Najafi. "Experimental and numerical investigations on a new developed Savonius turbine for in-pipe hydro application." Proceedings of the Institution of Mechanical Engineers, Part A: Journal of Power and Energy 234, no. 2 (2020): 195-210. https://doi.org/10.1177/0957650919854583

[30] Payambarpour, S. Abdolkarim, Amir F. Najafi, and Franco Magagnato. "Investigation of deflector geometry and turbine aspect ratio effect on 3D modified in-pipe hydro Savonius turbine: Parametric study." Renewable Energy 148 (2020): 44-59. https://doi.org/10.1016/i.renene.2019.12.002

[31] Ryosuke, Sonohata, Fukutomi Junichiro, and Toru Shigemitsu Toru. "Study on contra-rotating small-sized axial flow hydro turbine." Open Journal of Fluid Dynamics 2012 (2012). https://doi.org/10.4236/ojfd.2012.24A039

[32] Shigemitsu, Toru, Junichiro Fukutomi, and Ryosuke Sonohata. "Performance and internal flow of contra-rotating small hydro turbine." In Fluids Engineering Division Summer Meeting, vol. 55553, p. V01BT12A002. American Society of Mechanical Engineers, 2013.

[33] Shigemitsu, Toru, Yasutoshi Takeshima, Chihiro Tanaka, and Junichiro Fukutomi. "Influence of spoke geometry on performance and internal flow of contra-rotating small-sized hydroturbine." In Fluids Engineering Division Summer Meeting, vol. 57213, p. V01AT22A002. American Society of Mechanical Engineers, 2015. https://doi.org/10.1115/AJKFluids2015-22116

[34] Nan, Ding, Toru Shigemitsu, Shengdun Zhao, Tomofumi Ikebuchi, and Yasutoshi Takeshima. "Study on performance of contra-rotating small hydro-turbine with thinner blade and longer front hub." Renewable Energy 117 (2018): 184-192. https://doi.org/10.1016/i.renene.2017.10.046

[35] Ramos, Helena M., Alexandre Borga, and Mariana Simão. "New design solutions for low-power energy production in water pipe systems." Water Science and Engineering 2, no. 4 (2009): 69-84.

[36] Ramos, Helena M., Charlotte Teyssier, Irene Samora, and Anton J. Schleiss. "Energy recovery in SUDS towards smart water grids: A case study." Energy Policy 62 (2013): 463-472. https://doi.org/10.1016/j.enpol.2013.08.014

[37] Ramos, Helena M., Mariana Simão, and A. Borga. "Experiments and CFD analyses for a new reaction microhydro propeller with five blades." Journal of Energy Engineering 139, no. 2 (2013): $109-117$. https://doi.org/10.1061/(ASCE)EY.1943-7897.0000096

[38] Samora, Irene, Vlad Hasmatuchi, Cécile Münch-Alligné, Mário J. Franca, Anton J. Schleiss, and Helena M. Ramos. "Experimental characterization of a five blade tubular propeller turbine for pipe inline installation." Renewable Energy 95 (2016): 356-366. https://doi.org/10.1016/j.renene.2016.04.023 
[39] Nishi, Yasuyuki, Yutaka Kobayashi, Terumi Inagaki, and Norio Kikuchi. "The design method of axial flow runners focusing on axial flow velocity uniformization and its application to an ultra-small axial flow hydraulic turbine." International Journal of Rotating Machinery 2016 (2016). https://doi.org/10.1155/2016/5390360

[40] Nishi, Yasuyuki, Tomoyuki Kobori, Nozomi Mori, Terumi Inagaki, and Norio Kikuchi. "Study of the internal flow structure of an ultra-small axial flow hydraulic turbine." Renewable Energy 139 (2019): 1000-1011. https://doi.org/10.1016/i.renene.2019.03.004

[41] Alexander, K. V., E. P. Giddens, and A. M. Fuller. "Axial-flow turbines for low head microhydro systems." Renewable Energy 34, no. 1 (2009): 35-47. https://doi.org/10.1016/i.renene.2008.03.017

[42] Yusuf, Siti Nurul Akmal, Yutaka Asako, Nor Azwadi Che Sidik, Saiful Bahri Mohamed, and Wan Mohd Arif Aziz Japar. "A Short Review on RANS Turbulence Models." CFD Letters 12, no. 11 (2020): 83-96. https://doi.org/10.37934/cfdl.12.11.8396

[43] Ansys, C. F. X. "ANSYS CFX-solver theory guide." ANSYS CFX Release 15317 (2009): 724-746.

[44] Ansys. "ANSYS Fluent User's Guide." ANSYS, Inc., 2013.

[45] Cengel, Yunus A. Fluid Mechanics. Tata McGraw-Hill Education, 2010.

[46] Dixon, S. Larry, and Cesare Hall. Fluid mechanics and thermodynamics of turbomachinery. Butterworth-Heinemann, 2013. 